\title{
Peer-to-peer work in the digital meaning society 2050
}

\author{
Juho Ruotsalainen $^{1} \cdot$ Sirkka Heinonen $^{1}$ (D) $\cdot$ Joni Karjalainen $^{1} \cdot$ Marjukka Parkkinen $^{1}$
}

Received: 29 July 2016 / Accepted: 21 October 2016 / Published online: 3 November 2016

(C) The Author(s) 2016. This article is published with open access at Springerlink.com

\begin{abstract}
The article discusses possible futures of selforganising peer-to-peer work through four transformative scenarios constructed in the Neo-Carbon Energy research project. These futures images probe the futures of work from the perspective of peer-to-peer organisations and distributed renewable energy production. The scenarios lay a systemic view on the development of societies, studying how decentralised renewable energy with low costs could affect society and its social relations. We anticipate the emergence of a digital meaning society, in which the economy is based on the production of meanings and meaningfulness. The article analyses the results of a futures workshop on the futures of work by classifying them to seven core themes. The results of the analysis are compared to related implications for policy-making, and to the Millennium Project Work/Technology Scenarios 2050 for international perspectives. The article presents possible disruptions and key emerging issues, including the novel drivers for inequalities of peer-to-peer work.
\end{abstract}

Keywords Futures of work - Peer-to-peer - Transformation Scenarios $\cdot$ Digital meaning society $\cdot$ Low-cost renewable energy

\section{Sirkka Heinonen}

sirkka.heinonen@utu.fi

Juho Ruotsalainen

juho.ruotsalainen@utu.fi

Joni Karjalainen

joni.karjalainen@utu.fi

Marjukka Parkkinen

marjukka.s.parkkinen@utu.fi

1 Finland Futures Research Centre (FFRC), University of Turku, Korkeavuorenkatu 25 a 2, 00130 Helsinki, Finland

\section{Introduction - near-zero marginal costs and neo-carbon scenarios 2050}

A wholly renewable energy system can be achieved by 2050 . It would be based mainly on solar and wind energy and their storage technologies $[5,6]$. This would signify a major shift in how energy is produced and consumed. However, studies of new energy systems often neglect the social and societal aspects of the transition [29]. From a whole-of-society perspective, perhaps the most radical consequence of the renewable energy transition would be the plummeting marginal cost of energy - wind and solar energy are in principle free, once their fixed costs have been covered [35].

The falling marginal costs of energy would be one more addition to an intriguing group of events. Information and Communication Technologies (ICT) have dramatically decreased the costs of producing, processing, and distributing information. Thus the marginal costs of information have been close to zero for a while already [3]. As physical production is being automated, and as information is increasingly applied to material production processes, the marginal costs of physical production are also decreasing, and will probably continue to do so at an accelerating pace [30]. Together, these developments will have radical impacts on practically every sphere of society.

Automation, ubiquitous information and communication technologies, as well as renewable energy systems with near-zero marginal costs imply a future of abundance instead of scarcity $[11,30]$. This, in turn, hints at an upheaval in markets, price mechanisms, and organisation models, which are based on the assumption of scarcity. We may be entering a post-work and post-capitalistic society, where the necessary labour time of humans is reduced near zero, and where nonmarket, peer-to-peer, and collaborative commons models of organisation replace traditional organisations $[30,35]$. 
Falling marginal costs have levelled the playing field for small, grassroots actors. On this premise, Rifkin [36] anticipates the third industrial revolution, where production moves from large factories to small-scale workshops and cooperatives with the aid of renewable energy and digital production technologies, such as $3 \mathrm{D}$ printing. As a consequence, in the future production may divide in two: "necessary labour" conducted mainly by robots, and voluntary production by selforganising peers. Presently, peer-to-peer models are typically used to describe open digital collaboration projects, such as Wikipedia and Linux, but these principles can be applied to organisations in general, both physical and "virtual" [26].

In the Neo-Carbon Energy research project, ${ }^{1}$ four scenarios of a peer-to-peer society in 2050 have been constructed on the premise of renewable energies, automation, ubiquitous ICTs, and low marginal costs [21]. In all of the scenarios, the energy system is based on distributed solar and wind energy as well as energy storages, while production is organised as peer-to-peer models, as communities instead of hierarchical command structures. In the first scenario, Radical Start-ups, economy is driven by networks of start-up enterprises. Start-ups are often communities that have become companies. No clear lines between work and leisure, and between different startups exist, and open collaboration prevails throughout society. Still, many people are left out of the start-ups and have become marginalised. In the Value-Driven Techemoths scenario, the economy is dominated by a few technology giants or "techemoths" that offer resources, facilities, and platforms for self-organising employees, as well as all basic amenities from housing to leisure to education. As such, it is a more "closed" world than that of the Radical Start-ups, but (at least) within companies resources are shared freely. Then again, those who are not employed by techemoths are often socially excluded. In the Green DIY Engineers scenario society is organised around thriving local communities to survive an ecological collapse. Do-It-Yourself economy and practical mind-sets flourish, and smart scarcity has ensured many communities a relative abundance. As some communities live amidst poverty and scarcity, conflicts between communities are common. In the New Consciousness scenario, robotisation and ubiquitous ICTs have developed the farthest. Society is organised as global collaboration and open sharing of resources and information. Humans share a collective techenabled consciousness through ubiquitous communications, virtual reality, and rudimentary brain-to-brain communication.

\footnotetext{
${ }^{1}$ Neo-Carbon Energy is a joint research project of Lappeenranta University of Technology (LUT), Technical Research Centre of Finland (VTT) and Finland Futures Research Centre (FFRC), University of Turku. The project investigates a $100 \%$ renewable energy system based mainly on solar PVs, wind, storage technologies, and using carbon captured from air to produce synthetic hydrocarbons. The futures research part of the project anticipates the societal implications of the energy system. The time frame of the project extends to the year 2050.
}

In all of the scenarios the structure of production is different from today. As material production is highly automated, or restricted to basics as in the Green DIY Engineers scenario, the role left for human labour is to produce cultural meanings and meaningfulness - i.e. creative labour. As a societal framework for the scenarios, we propose a concept of meaning society, succeeding the information society. In the meaning society, economy and society are not built so much around information and industrial production than on the production and consumption of cultural meanings as well as on interactions between people. The main need or "demand" of citizens is to increase the meaningfulness of their lives, both socially and individually. This is achieved through the production and communication of shared meanings. As material production has been virtually fully automated, information and communication technologies as well as digitalisation are used to "enhance" the production of meanings and meaningfulness. In the present, social media can be seen as a weak signal of such development, as entire business models of social media companies are based on the production, consumption, and distribution of meanings and meaningfulness [28].

Interestingly, scenarios on work and technology for 2050 by the Millennium Project (from here onwards referred to as MP) arrive at quite similar conclusions [19]. The set of MP scenarios is used in this article as a topical framework to discuss the results of the analysis in an international context. The first MP scenario, It's Complicated - A Mixed Bag is a business-as-usual trend projection of the increasing acceleration of change with both intelligence and stupidity of decisionmaking. It resembles Radical Start-ups and Value-Driven Techemoths scenarios, as all of them deal with a future that is polarised between the well-off and the more or less marginalised, and where corporations have a lot of power. In the second MP scenario, Political/Economic Turmoil - Future Despair, governments do not anticipate the impacts of artificial general intelligence and have no strategies in place, when unemployment explodes in the 2030s. This scenario resembles Green DIY Engineers scenario, both being collapse scenarios with anarchic tendencies. The third MP scenario, If Humans Were Free - The Self-Actualization Economy, is a "transformation" scenario where governments anticipate the impacts of artificial general intelligence, gradually take into use universal basic income systems, and promote self-employment. This scenario is akin to all four Neo-Carbon scenarios but comes closest to the New Consciousness scenario, as both of them emphasise a general artificial intelligence, self-employment, and self-actualisation.

In this article, we will have a closer look on the possible futures of work outlined in the Neo-Carbon scenarios [21] by presenting results from a futures workshop "The Fuzzy Futures of Neo-Carbon Work". In order to give theoretical background to workshop results, we present the basics of self-organising peer-to-peer production in chapter 2 . These 
ideas are revisited in conclusions (chapter 5). The workshop results are introduced in chapter 3 . The implications of these findings, their policy aspects, and relations to the MP scenarios are discussed in chapter 4 . We conclude the article by reflecting the workshop results on the central themes of peer-to-peer work described in chapter 2 , on the concept of the digital meaning society, and issues of contemporary political relevance.

\section{The futures of work as self-organising peer-to-peer production}

Robotisation and applications of artificial intelligence are perhaps the most topical questions of the futures of work, as they replace many of the jobs done today by humans, and thus deeply transform practically every industry [7]. However, views on the outcome of the upheaval are polarised. Half of the respondents (48\%) of an expert study [33] envisioned that by 2025 new technologies have replaced significant amounts of blue- and white-collar jobs leaving many unemployed. The other half $(52 \%)$ anticipated that human ingenuity creates new jobs at a rate that ensures jobs and decent income also in the future. Susskind and Susskind [41] expect the transformation of work to be incremental, rather than an overnight revolution.

To tackle the challenge posed by technological and economic changes, new visions for the futures of work are urgently needed. Despite prevailing inequalities, as many parts of the world are becoming more affluent and production more efficient, largely due to new technologies, there will be a growing opportunity for economic arrangements that maximise other values than mere economic ones [20]. Brynjolfsson and McAfee [7] anticipate peer-to-peer production as a promising possibility in opening previously unavailable economic opportunities and giving people something meaningful to do in an automated future. Peer-to-peer is an encouraging model for a post-work or post-capitalistic society, as it does not necessarily require markets and monetary transactions to work properly. Peer-to-peer production can be defined as a distributed network of free participation of equal partners [32]. Participants are engaged in the production of common resources without monetary compensation as the keymotivating factor. Peer-to-peer production creates Commons (shared, free resources), which rely on social relations rather than pricing mechanisms or managerial commands to allocate resources [32].

Because peer-to-peer production is based on informal social relations, its organisation model can be described as open collaboration of self-organising communities. Based on a literature survey, Forte and Lampe [14] describe open collaboration as systems which $(a)$ support the collective production of an artefact, $(b)$ through a technologically mediated collaboration platform, $(c)$ present a low barrier to entry and exit, and $(d)$ support the emergence of persistent but malleable social structures. In the following we survey briefly these features and interpret their implications, which are in line with our hypothesis of the meaning society, as all of them emphasise new kind of meaningfulness embedded in work.

The collective production of an artefact $(a)$ often strives for originality [14], which implies that products are not aimed at the mass market but for smaller audiences that share common tastes and values with the producer community. This points to a future where the public sphere of work and economy merge with the private sphere of leisure - producers and consumers would not be separated to the extent they are today. Producers and consumers would share a common community, and often they would be the one and the same. This uniqueness of the products of peer-to-peer production might make it an alluring opportunity for the future of work. Budhathoki and Haythornthwaite [8] state a shared "unique ethos" of distinguished ideals, values, beliefs, and sentiments in open collaboration projects as one of the key motivations to participate.

Open collaboration typically takes place on technologically mediated platforms $(b)$ because networked communication tools allow the participation of massive numbers of users, an efficient allocation of tasks, and highly developed specialisation. However, "tightly coupled" tasks that require a lot of iterative feedback between participants may demand physical interaction instead of mediated [14]. This implies that the more unique the products, the more open collaboration takes place in physical environments. This points towards a future in which work is organised around communities instead of "workplaces". A delicate division of labour enables supplying to niche demand.

Few barriers of entry and exit exist in open collaboration (c) [14]. This promises an easy access to work. Newcomers choose actively to attend, and are internally motivated by e.g. reputation building, enjoyment, or a need for a product. As a project proceeds, active participants tend to develop a shared identity and are increasingly driven by community, co-learning, and professional development. However, this poses a challenge for the socialisation of newcomers, for whom it can be hard to understand the norms, social structures, and what needs to be done. Counter intuitively, open collaboration can sometimes be exclusive [14]. This implies new kinds of inequalities in the future of work, where one's lifestyle and values become qualifications instead of "objective" competency.

Open collaboration is based on persistent, but malleable social structures $(d)$. This emphasises the importance of communication flows between participants. Often social structures of this kind are achieved through the negotiation and renegotiation of community norms and administrative structures. Such structures require leaders as any organisation does, but leadership is often shared and distributed [14]. This 
implies a future organisation of work that is based on ubiquitous and distributed communication, and to an increasing symbolic nature of work.

Peer-to-peer-production and open collaboration can be anticipated to become increasingly common in the future especially due to economic, technological, and cultural drivers. Economic value is generated more and more from immaterial production and the creative industries (economic driver). Ubiquitous information and communication technologies allow new kinds of open and peer-like organisation structures, and have placed the means of production in the hands of citizens (technological driver). People's values are shifting towards self-expression and inner motivations in work (cultural driver) - open collaboration especially includes such motivators as self-actualisation, recreation, and fun [8].

Along these lines, in the following we describe the basic logics of peer production and open collaboration according to Yochai Benkler [3, 4]. Benkler [4] claims that due to different drivers, peer-to-peer, nonmarket, and non-proprietary production may become not only possible, but the dominant form of production and organisation in the future. Benkler [3, 4] bases his claim on the assumption that human creativity and the economics of information have become the core structuring feats of our economy.

Such production will arise as the third way to organise production along with the market and the bureaucracy, due to the nature of information. In markets, the allocation of production is done through price signals, while in bureaucracy according to the management decision-making. In the peer-topeer model, allocation is self-organised: producers decide for themselves what they do, how, and with whom [4]. Benkler claims that self-organisation is the most efficient way to deal with information products.

Information and culture are public resources (commons) by nature, as they are non-scarce and their consumption does not prevent others to consume them - they are non-rivalry. The marginal cost of information products is thus near zero. Supply and demand, which set the price for a product, assume scarcity. Because information is non-scarce and non-rivalry, intellectual property rights have been established to give information products a price. This, however, leads to underutilisation of information. If the price of information is low or free, it spreads more widely and is put to use more efficiently. Production of new information is based on the existing information, and thus the more information is available, the better it can be refined as new products [4].

The scarce resource that remains in immaterial production is human creativity, which is utilised best in an environment of free information and self-organisation. This is due to two reasons especially. As creativity and culture are built on existing human capital and cultural resources, the more cultural contents are available, the better they nourish creativity and production of new culture. Self-organisation of producers ensures the free flow of information better than traditional organisations, which tend to keep information to themselves. Second, creativity is very hard to standardise and administer by managers. People know their creative capabilities best themselves, and thereby the best way to organise creative labour is to let people decide for themselves in which projects to work on and how. Furthermore, when information flows freely, potential producers and suitable projects can be matched efficiently [4].

Such "new economy" of peer-to-peer production and open collaboration would stretch also to the sphere of culture and values. According to Benkler [3], the open, networked information environment would make culture more democratic, participatory, transparent, and malleable. (For the network society see [10].) We would see an emergence of a new folk culture where, by participating in the creation of shared culture and finding of meaning, self-organising citizens would also create culture that is much more of their own than the mass-media-type of industrial one [3]. As identities and meanings are always co-constructed, and efficient ICTs allow for more fluid communication, people would be better able to form communities with like-minded peers [9]. In the new "folk culture", identity would be based increasingly on such grassroots communities instead of the nuclear family and the industrial organisation. Individuals and their communities would thus have increased capabilities as the core driving forces of the networked information economy.

\section{Results of the futures clinique "the fuzzy futures of neo-carbon work"}

On April 13th 2016 in Helsinki, a futures clinique (a specially structured futures workshop, [23]) was held to probe the futures of work in a 2050 world of automation and distributed, low-cost renewable energy. The year 2050 was chosen as it is the timeframe for the NeoCarbon project (see endnote $\mathrm{i}$ ), which is distant enough in the future so that the effects of automation and renewable energy will have had time to settle. Around 40 experts from different backgrounds - researchers, officials, company representatives, and students - participated in the event. Many of the experts had a background in energy research and business, but there were also experts e.g. on work life and media start-ups. Students had background in engineering, business, and Futures Studies. The wide background of participants aimed at analysing the futures of work from as many perspectives as possible. However, the composition of the participants was biased in the sense that there were no unemployed participants. All the participants can be socio-economically described as middle or upper middle class and as employed in expert occupations. 
There were five groups, each of which worked on one of the Neo-Carbon scenarios described in the introduction of this article. For the New Consciousness scenario there were two groups as this was the most popular scenario among participants, and those who wanted to work with this scenario had to form two groups. The participants were sent a short description of their group's scenario beforehand.

Three foresight methods were used in the futures clinique: futures wheel, futures image, and futures table. This article presents the results of the futures wheel session, which was the main method in probing the futures of work in the groups' scenarios. Futures wheel is a mind map like tool developed by Jerome C. Glenn of the Millennium Project (for more information on the method see Glenn (2009) [17]). The futures wheel was chosen as the main method for this futures clinique, because it enables coming up with new ideas on the theme in a cooperative and flexible manner. The futures image and the futures table were chosen to encapsulate and elaborate the core idea from the futures wheel. The futures wheel consists of two consecutive circles. The use of the circles can be modified according to the needs in each case. Ideas are written on post it pads, which are then placed on the circles of the wheel. In this futures workshops the group work began from the centre of the wheel, where each group member wrote their personal ideas on ideal work in the group's scenario and presented them to others. This outlined preferred futures of work. Next, the groups discussed what work could be like in the given scenario's future, in both positive and negative aspects. The ideas were placed on the inner circle of the wheel. This depicted possible futures of work. After finishing the inner circle, the group discussed and came up with possible consequences of the work they had anticipated in previous phases, for instance as concrete products, organisation models, companies etc. These ideas were compiled on the outer circle of the futures wheel.

Because usually not all ideas presented in futures workshops end up written, each group's discussions were recorded. After the event, the moderators transcribed the discussions on a Word document. In the following the transcribed results of the futures wheels are classified into seven categories and synthesised as a projection of the future of work. All the ideas presented in the following have been compiled and interpreted as a cohesive text. Hence this article offers a methodological advancement to futures workshops. Often the problem of futures workshops is that they present a plethora of disconnected ideas. This article shows how the ideas can be combined as a comprehensible whole by first documenting all the ideas as transcribed text - not only as post-its, which often leave crucial points of view out as the space of a post-it is limited - and then refining and synthesising the ideas by writing them as a futures projection. In this article the concept of futures projection is introduced and experimented as a description with similarities to futures image, but with more room for alternative and even controversial elements within the text. In the classification and analysis the different phases of the futures wheel are not treated as separate. Thus, to provide a comprehensive view, the futures projection includes elements from possible and preferred, as well as non-preferred futures. The seven categories, that also form the structure of the futures projection, are depicted in Fig. 1. These elements, as results of the futures clinique, are discussed upon the features of peer-topeer work, as depicted in chapter 2, and then in terms of possible policy implications, with further reflections in the conclusions.
Fig. 1 The seven themes of peerto-peer work in the digital meaning society 2050

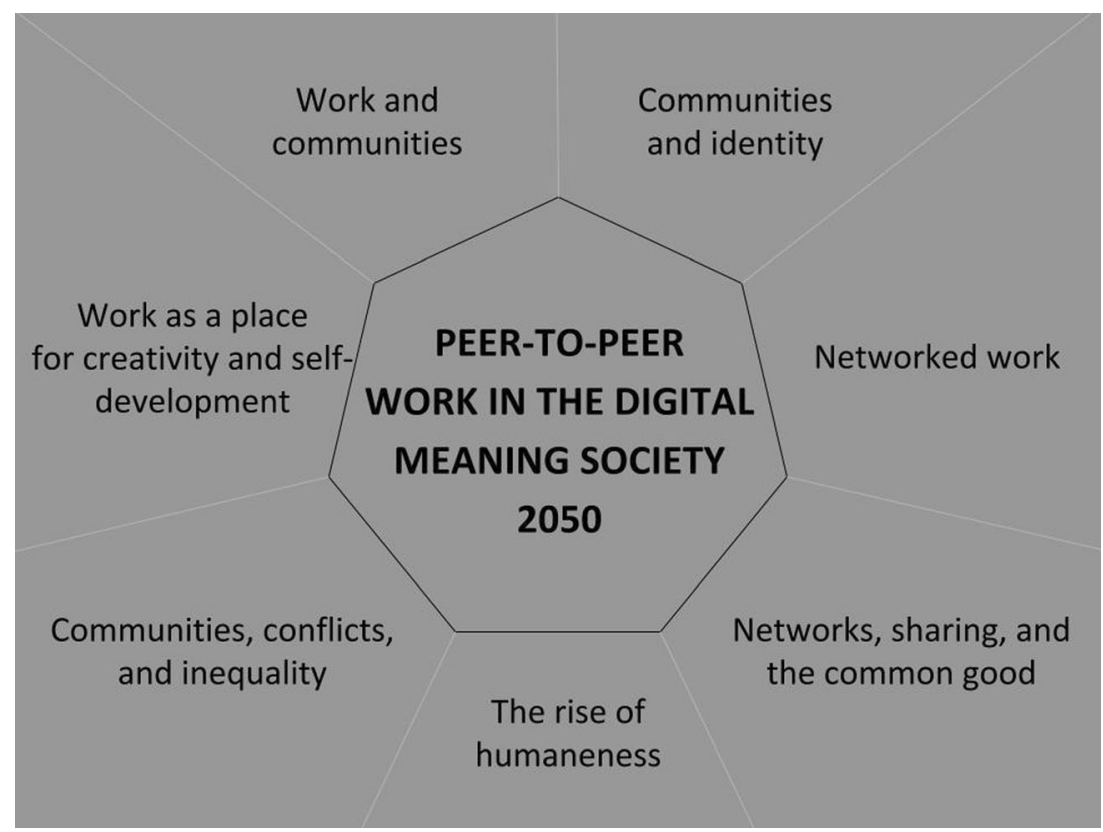




\section{A futures projection on peer-to-peer work in the digital meaning society 2050}

\section{Work as a place for creativity and self-development}

If robots took care of most of the material production and menial jobs, work done by humans would fundamentally change its nature by moving towards immaterial needs - such as creativity and belonging. Instead of material needs, such work would satisfy first and foremost those of selfactualisation and self-expression. In an ideal situation work would be meaningful, creative, and purposeful, and a source of experiences and self-development. It would allow constant learning, and tasks would be modified as one develops. No sharp division between work and leisure would exist, and a person would be seen as an individual and a human being also when he or she is working, instead of a cog in the wheel.

Creative work of self-development would be built from the bottom-up. Management would be replaced by selfmanagement. Workers would be internally motivated, and the role of managers would be to help workers reaching their potential and personal goals. Companies' values would reflect those of their workers, not vice versa. Like individuals, enterprises would pursue other goals than profits only. Companies would be partly freed from the requirements of the market, as new kinds of "free enterprises". Instead of being seen as contradictory, doing good and making a profit would merge. Businesses would be more like adventurous test labs and condensations of intellectual, social, and economic resources, rather than profit-maximising entities of today.

Work in such companies would require workers to selfdefine their jobs. Only then could work correspond with citizen's personality, gifts and interests. This implies that supply creates demand, not the other way around. Production according to demand would not be truly independent. Instead, people would do their "own thing" manifesting their personality, and trust that resulting "authentic" products would find their markets. A pivotal skill in this kind of a world would be to "find one's thing". However, those unable to self-define their work could easily be marginalised.

Although the kind of work described above seems highly individualised, its most fundamental feature would not be individualisation, but the rise of communities. Individuality and creativity stem from social relations and a shared culture. To maximise their creativity, people would work at the same time independently and with others, learning from each other, and establishing ad hoc teams according to changing needs and preferences. Work would provide experiences not only for oneself, but for one's acquaintances and communities as well. When everyone does things they do best and express their individuality through work, they also contribute for the common good.

\section{Work and communities}

If work became first and foremost self-expression, communities would consequently replace organisations, as they offer better possibilities for individuals to self-define their jobs. The separation between the different spheres of life and the sectors of society would wither away, at least to some degree. Work and leisure, private and public, and an individual and the community would merge together as an organic whole. Individuals and communities would thus become the units of exchange instead of organisations. A traditional workcommunity would transform into a leisure-like community or a "community of passion". Work would be done and developed together. Belonging to a community or a company might even be one's right as a citizen - you are born into, for instance, a community-like start-up.

Producers and consumers would have a shared life world. There would be a personal, creative bond between the provider and the so-called customer. Work would be mutual cocreation between workers and customers. Demand would define supply in much more intricate ways than today.

An artificial intelligence or different algorithms could be enablers for work that is at the same time individualistic and collective. In practice, this could mean for example a platform that connects individuals with the same interest, tastes, goals etc. with each other - enabling, for instance, a community for the curious. Such platforms would allow flexible forms of occupation. At different stages of life an individual could be an employee, an employer, a freelancer, and everything in between, also working flexibly in different industries.

\section{Communities and identity}

The kind of "community work" described above would not serve the purposes of production and self-development only, but would also help individuals to construct identities in a meaningful way. In the future, identities, meaning and purpose could be based first and foremost on different communities, and on work done at these communities. Different communities could for instance provide a "personal mission" for individuals, as a basis for a stable and constant identity.

The rise of communities would probably not mean a return to uniform cultures. On the contrary, as citizens would cocreate their communities and corresponding identities, culture would become much more diverse than today. Freedom to consume what one wants could transform as freedom to choose one's way of life. People would not belong to one or a few communities only, but to many different and constantly changing ones. Different media, in turn, could specialise to serve different communities, and identities of individuals and media could enmesh. Media would have their own distinct voices to which different individuals could relate to according to their own tastes, ideas and values. 
Once again, a person's ability to "know thyself" would be emphasised. One's personality would steer him or her to choose certain communities and influences over others. This assumes that people know what they want from their lives in the first place. Life-coaching could thus become immensely important - life coaches could even transform as "priests of the future", replacing religious figures by secular spiritual guides.

Regardless of the relative continuity offered by communities, a networked, peer-to-peer world would probably be more chaotic and more in flux than the present world. This could lead to many yearning for stable and tight communities, instead of constantly changing ones. Perhaps most would like to skip between communities, but some could wish to belong to something permanent and clearly bounded. This longing for stability could lead to "bubbles" within which individuals would socialise only with the like-minded and shut the rest of the world outside. Another possibility is that local communities would be replaced by a "global village", a cosmopolitan identity, or even by some kind of new world religion. A global identity could offer the base on which different microidentities would be tied together.

\section{Networked work}

If communities were the basic units of new work, the general organisation model for work could be provided by networks. Rigid bureaucracies would be replaced by organic, porous network structures, and different communities would be linked together by interlocking networks. Resources would be shared within networks: workspaces, tools, information, et cetera. Sharing could be global, local and regional. This is because new technologies are so complex and are needed globally, for instance to tackle climate change, that they require global development efforts and global distribution.

Glocal (global and local) networks could mitigate the "sectarian" tendencies of close-knit communities as the structure through which people could swap between different communities. Networks would make communities and collaboration more diverse. Networks would be open, and allow working where, when, how, and with whom one wants. In other words, networks would ensure that individuals retain the freedom to choose for themselves and are not embraced by their communities too dearly. Then again, paradoxically, networks would dissolve stable social structures - such as nation states and their loss could make people want to belong again to "closed" communities. If networks make societies and boundaries within them more fluid, people may seek emotional shelter from firmly bounded communities. The fact that networks dissolve clearly defined boundaries could be deemed problematic in other ways as well. Because networks would spread virtually everywhere and cover every sphere of life, work and leisure might become inseparable even if people would sometimes prefer keeping them separate.

\section{Networks, sharing, and the common good}

If material production was highly automated, people would not have to work as much as today to earn their living - if, for instance, universal basic income guaranteed the basic standards of living. This would create a fertile ground for altruism and sharing. Doing good and working for others could be an alternative to paid labour as a source of meaningful activities.

In a world of sharing and networks, money and other resources might be partly redefined as possessions of the network instead of private property. Furthermore, value would not be understood only as monetary, but as e.g. ethical, aesthetic, and social value as well. The successful ones would want also others to succeed because networks and communities had enabled their success in the first place. Once one has earned enough money, he or she may donate at least some of it away to help others. Networks and communities could also provide a safety net in times of hardship, resembling social arrangements in developing countries, where a person who earns money often finances his or her community. There would be solidarity in networks that seems foreign to traditional notions of competition. Networks would function more on principles of open source than property rights. Growth would be seen as sharing and spreading of capital instead of its private accumulation. In an ideal situation resources would be allocated so that more creative human potential could be harnessed, instead of keeping them in the hands of a few.

A successful entrepreneur would be a kind of a hero, who brings tax income and other value to the society. Such "hero entrepreneurs" would form a nexus around which communities and networks would evolve. Money would not be the main motivation for success, but instead e.g. acquiring deep knowledge and reaching ethical goals. Entrepreneurs of this kind would not focus, for instance, on developing "a new camera app", but on solving the world's problems and providing for the common good. The incentives for such efforts would again probably not be material, but for example prestige, social connections, and pure altruism. People would also choose where to work according to values and goals they consider important, not according to monetary compensation.

Situation of this kind would redefine wage. Work would not be seen as means for subsistence but as "general labour" comprising of all creative acts. Compensation of a more social work would also steer towards more social conceptions. People would seek spiritual and social fulfilment instead of material rewards. To be respected is a basic human need that cannot be satisfied through material compensation. Wage could be, for instance, quantified social status or social capital (social media "likes" as a rudimentary, present example). Belonging to a desirable (work) community and the 
opportunity for meaningful work could often be a sufficient compensation in itself. People would mostly be involved in tasks they would do voluntarily and out of passion, regardless of payment.

Work could thus be divided in two: half of the time people would work as paid labour, and half of the time in sharing economy and voluntary work. Enterprises could also take part in the sharing economy - the whole economy could at least to some degree be based on bartering, with no monetary transactions. If people had plenty of meaningful activity, they might even not want material things as they do today. A virtuous circle might thereby emerge: when people receive help from others, they also want to give back.

A major question is what should happen so that a postmoney world would be possible. What is the path from today to this kind of future? How does economic competition function and how is value created in this kind of world? These questions could be addressed in further studies on the nature and future possibilities of 'sharing economy'.

\section{The rise of humaneness}

An interesting theme in the futures clinique was the simultaneous emphasis and downplaying of the role of technology. Future society was seen not only as digitalised but also as thoroughly technologized. However, technology would be integrated seamlessly into environment so that it would be "discreet" and mostly invisible. Technology would become more independent so that it would work in the background without a need for human intervention. This would free people to interact with each other instead of machines. Furthermore, due to the development of artificial intelligence, technology would transform as less mechanistic and more human-like. Technology would be able to learn by itself and people could communicate with technology in the same way they communicate with each other. Our relationship with technology could thus become more intimate and effortless than today.

As machines would automate many tasks done today by us, humans would be freed to use and develop their human skills, those that machines would not yet possess. "The revolution of robots" could be succeeded by "the revolution of humans". Creativity and social intelligence would become even more pivotal than today. Emotion, empathy, and interaction would be emphasised. Humans would ask questions, set goals, and invent new needs, and the role of robots would be to help realising these plans. This would be a kind of a technologyassisted "back to nature" future in which humans would cultivate those very attributes that make us human.

\section{Communities, conflicts, and inequality}

The emerging automated peer-to-peer future would probably have its own social problems and inequalities. If the economy, for instance, was built strongly on start-ups, people would have a low entry point to start their own business or to join a fledgling company. This could mitigate unemployment and distribute wellbeing in an equal way. However, the system could be harsh on those who do not assimilate in the start-up culture requiring "successful" and high-performing individuals. If an individual was for any reason unable to succeed, he or she might easily become marginalised. Furthermore, in a society revolving around start-ups and other "community companies", the companies provide a community, and communities are often the way into the companies - it is a chickenor-egg situation where those outside start-ups and other companies would be in an inferior position to become members of a thriving community.

Unequal positions apply to communities as well. In the future of multitudes of groups one belongs to, people may not be in unequal positions as individuals but according to their communities. Competition between communities may intensify in a world of free information flows and global competition. Specialisation would thus become even more crucial than today, requiring communities to hone their skills as better than other communities.

Specialisation requires the division of labour. If the division of labour proceeds, society would become more plural than today. Tastes, ideas, and values would become more progressively diversified. A peer-to-peer society would thus be more fragmented than today. However, in such a society people would be more dependent of each other as well. The more communities, companies, and networks specialise, the more they need to exchange products and services. This creates "organic solidarity" that binds the fragmented society together.

Despite co-dependency, a fragmented society might pose new societal challenges. If the world is divided into numerous networks and communities, can a consensus on how society should work be achieved? Tribes enabled by social media may erode the role of industrial institutions, such as the judicial system and the mass media. People have forgotten "the dark" side of communities and tribes, such as sectarian narrowmindedness and unfairness towards other communities or tribes. A positive future in this respect could be a fusion of "traditional" communities or tribes and modern institutions, combining the best elements from both.

As a result of a shattered public sphere, expert knowledge and authorities can lose their power and status. Each community and network could have their own notions, knowledge, and morals. Traditional media as gatekeepers and definers of the truth would be subverted by individuals communicating with each other directly. Disinformation might spread more rapidly and have various adverse effects. Some groups might even seek to dominate others, for instance by using means of information warfare or by programming malevolent robots.

In a world of material and energy abundance the current competition of economic status might become meaningless. 
This, however, does not mean that competition will vanish. Perhaps people would compete on cultural and social capital? Those with the most refined taste and best social relations would be the new elite. Success requires that one is autonomous, active, and self-imposed - is able to manage one's life, understands what he or she wants, and knows one's strengths. Those with the most knowledge - including knowledge about oneself - would thrive the best. This applies to communities as well as individuals. Social and cultural inequality can also manifest itself as "qualitative unemployment" in the sense that the not-so-well-off would have to work in jobs that do not allow self-expression and satisfying other "higher" needs.

People often seek emotional security from tight communities. If the world becomes increasingly chaotic and insecure due to fragmentation of culture and values, religious fanaticism can become alluring for many. Fundamental religious views could offer a solid, unchallenged base on which to build one's life. A less radical alternative is the rise of "gurus", religious or otherwise. In economic communities, for instance, a charismatic character may become the centre around which the community revolves and develops. Besides economic security, people would seek emotional security from such persons. Thus, in practice power may not be as evenly distributed, as people today tend to think of grassroots organisations.

\section{Discussion - the role of politics and policy-making aspects}

The future is made by the decisions taken today [1]. This underlines the policy-making aspect of the possible futures of work. Our futures clinique findings reflect the importance of human-centeredness in an increasingly technology-aided peer-to-peer society. Some of the issues mentioned above have been thought to be addressed by the state with legislation and policies, as principles that can be encouraged, while certain emerging issues may be best handled directly at the workplace - and left to the self-organising communities. This implies that state might have to assume rather an enabling instead of an authoritative role. Beyond merely a technocratic issue, political alignments and swings will surely have an influence how these dynamics are interpreted across countries and societies. Overall, as work will be distributed differently in the future, flexibility of the labour market has to be controlled in an employee-friendly way [24]. The societal implications of the seven presented themes, as depicted in chapter 3 , are in part discussed here by reflecting the Millennium Project's Future of Work/Technology 2050 scenarios [19].

Ensuring a creative working life environment has traditionally been handled in the working place - could it therefore be difficult to mainstream as a policy prescription? (Creativity and self-development, see ch. 3) The cognitive and psychological aspects of workplace productivity and satisfaction are connected to the uptake of novel technologies and working culture. In principle, empowering individuals and providing relevant opportunities allow the harnessing of their capabilities [31, 39]. Self-awareness of one's skills, collaboration, and creativity-related "soft" aspects of work can be taken into account in the training and re-training of citizens. Public sector can have a role in this, in addition to assuming emerging technical competencies and collaborative tools. It's Complicated - A Mixed Bag MP scenario depicts how e.g. online self-employment training programs could enable finding meaningful work and lifestyles. In turn, if humans fail to become apt in living with the ever-growing connectivity [12, 40], mental strain can be helped with new workplace rules and practices. Notably, in the If Humans Were Free - the SelfActualization Economy MP scenario, the shift from employment culture to self-actualisation economy is fostered especially by the creative class.

With the increasing complexity of society, governance is expected to be flexible to different life situations of citizens. (Work and communities, see ch. 3) Therefore, in order to policies to be just amidst a changing work-life context, the social contract between the state and its citizens may have to be renegotiated. MP scenarios claim that basic income policies could be in place in several countries, but perhaps not yet universal, by 2050 . It will be a major leadership challenge to transform social protection systems and related institutions responsive to ever flattening hierarchies. But, in principle, when imagining how to react to the distributional effects of automatisation, Susskind and Susskind [41] argue for Rawlsian egalitarianism: if a person has to choose behind 'a veil of ignorance', most people prefer a society where most medical help, legal advice, news, business assistance, and so forth are broadly available, to one where property is only owned by the few.

To push for change, environmentally conscious tech-user millennials will want feedback from their endeavours [34]. In addition, the growing diversity of cultures as an outcome of globalisation could make communities difficult and complex for the public sector to govern. (Communities and identity, see ch. 3) The transformative MP scenario If Humans Were Freethe Self-Actualization Economy suggests that the sharing economy will extend from services to sharing social realities between people, further diversifying cultures. Then again, a high level of tolerance is somewhat a liberal idea and, as mentioned, cultural silos are likely to ensue. Clearly, some of such rifts are already visible today. Policy-wise, if automatisation kills jobs and disproportionately leverages certain groups, 'push' may be needed to support and sensitise groups that are slower to endorse openness to change than the forerunners. Taking care of the underdogs of in a globalised, automatised world may be the next needed affirmative strategy for states. Some of these groups, in particular, have been strongly tied to their community, local identity, and 
work, which may explain their reluctance to change. These mixed, even polarised, dynamics will also affect a significant number of young people entering future workforce [25].

As for the supply and demand of future labour, state can enable the providing of platforms for talent matching. However, if it fails to do so, this suggests that private and third sector may have to fill in. New initiatives and strategies by labour unions are found necessary in both the MP and NeoCarbon scenarios - if they wish to retain their relevance for the workers [19, 22]. (Networked work, see ch. 3). On the other hand, one identified problem in our futures clinique concerns the struggle that nation-states have in retaining economic value to provide for their citizens in a globalised platform economy. In a networked world, the transparency of revenue generated and tax revenue collection may become even more complex. Should basic income be in place, the MP scenarios suggest nine streams of tax collection to finance it: combatting tax havens; value added tax; wealth created by the emerging technologies; taxation of robots; leases and/or taxes from national resources; international financial transfers (akin to Tobin tax); universal minimum corporate tax; and by taxing corporations that are at least partially state-owned.

Citizens' possibilities to work while solving societal challenges may require novel and more flexible mechanisms. In order to deliver on such aspirations, companies may have to find novel business models that allow them to continue to make money, while allowing their employees to realize their aspirations for meaningfulness and saving the world. In the past, governments have already valued voluntary work and supported innovative, value-driven endeavours - e.g. through development policy. (Networks, sharing, and the common good, see ch. 3). Ironically, until recently the service economy debate itself has developed independently of the sustainable development question [16]. Despite the intangible nature of services, automatisation and big data increase data consumption and storage needs, and consequently, energy use. Energy is one of Millennium Project's Global Challenges [18] and a recently declared UN Sustainable Development Goal \#7 [42]. The key message in Neo-Carbon Energy scenarios is to reveal the underscoring of decentralised renewable energy as a driving factor of the service economy. This is a sector whose growth - in itself - can create new jobs and make creative growth less based on the physical extraction of resources $[22,36]$.

A collectively expanding solidarity is perhaps an overarching theme that seems to bind the ideals of work (The rise of humaneness, see ch. 3). For instance, if work is to bring meaning to personal life in a technologized society for broader populations, work places must have encountered valuedriven changes - across sectors. Altruism requires a level of trust in a society, and ethical entrepreneurs, for whom salary is a less significant factor, will better flourish, if precarity is mitigated. If humane values genuinely fuel empathy across the technology, society, and nature [37], the well-being and meaningful lives of citizens have been ensured. Economic, labour, and social policies, again, have a supportive function. According to MP scenario If Humans Were Free - the SelfActualization Economy, guaranteed universal basic income could prevent the social chaos resulting from massive unemployment.

Our futures clinique, which focused in the novel peer-topeer work ethos, did less to address the cultural divide of the work-life of post-industrialist and traditional societies. New conflicts might arise, when this ethos meets and challenges old authoritative work ethics and management styles. Another issue is employment and the question of how many jobs will be created and how many replaced, as an outcome of automatisation, subject to intense speculation with few reliable answers, which makes the issue somewhat challenging for policymakers to confidently anticipate $[13,27]$. (Communities, conflicts and inequality, see ch. 3) Different citizen groups will have different ability to benefit, and widening inequalities have to be tackled, as most growth continues to take place in urban agglomerations. To avoid political and economic disturbance and the resulting misery, as warned by MP's dystopic scenario Political/Economic Turmoil: Future Despair, it must be ensured that the peer-topeer ethos allows the lives of everybody change, not only of those well off. Therefore, a genuine liberation would be to have emerging technologies work for and support the selfactualisation of masses living in a peer-to-peer society.

\section{Conclusion - reflections of the futures clinique results upon peer-to-peer work and the digital meaning society}

For the purposes of this article, the results of futures clinique "The Fuzzy Futures of Neo-Carbon Work" were classified into seven themes constituting a projection on the futures of peer-to-peer work. The themes and the projection are summarised below:

- Work first and foremost fulfils immaterial needs of selfexpression (Work as a place for creativity and selfdevelopment).

- The traditional work-community has transformed into a leisure-like community (Work as communities).

- Work communities serve as a means to construct new identities to replace old ones, based on e.g. traditional professional occupations (Communities and identity).

- The organisation structure of work is a network, the role of which is to link different communities together and enable sharing of resources (Networked work).

- Work is altruistic, and solidarity prevails without being confined to one's community, company, or workplace (Networks, sharing, and the common good). 
- As ubiquitous intelligent technology takes care of routine tasks and expands our capabilities, humans can concentrate on tasks deemed meaningful (Rise of humaneness).

- However, grassroots peer-to-peer future does not necessitate an equal society, but instead new inequalities, connected to cultural and social capital, as well as to the communities' people belong to, may arise (Communities, conflicts, and inequality).

Interestingly, all the results of the futures clinique go in line with our hypothesis of the digital meaning society described in the introduction. In the futures projection, the main goal of workers and companies would be to produce meaning and meaningfulness, for others and themselves. Meaningfulness would stem from the workplace communities instead of corporate culture or predefined professionalism. Networks would ensure that communities are not isolated and that cultural meanings circulate freely, aiding in identity construction. The ethos of providing for the common good would strengthen meaningfulness. So would the "rise of humaneness", as highly developed automation would leave to us the tasks through which we can express our humanity. This is to say, that digitalisation fosters the transformation, which reaches far beyond mere technological aspects.

Meaningfulness presupposes a "unity", as people feel their life has purpose and meaning when they see themselves as a part of and work for something bigger than themselves [2]. According to Fricker [15], to re-establish meaning we have to re-establish meaningful connection - to each other, other species, and the world at large. Peer-to-peer work of communities may help in achieving this "unity", because it implies that the separation of different life spheres ceases [26, 32].

Supply and demand would become inseparable, and work could be described as prosumeristic, without division between a producer and a consumer. Consumed goods, especially information, are used in turn to produce new goods [38]. Demand would rise from the shared culture and needs of communities. As the "life world" of individuals are tied to their community, their members would intrinsically know the needs of the community. Peer-to-peer organisation would result in "the new folk culture" [3], where society is not divided into distinct areas (e.g. home and factory). Instead, the whole of society becomes a "factory".

The pursuit for meaning and meaningfulness is also reflected in the aspiration towards independent and authentic production, as anticipated in the futures clinique. This is similar to the notion of the shared "unique ethos" as a motivation to participate [8]. Such peer-to-peer work would be "tightly coupled", i.e. requiring a lot of communication between participants [14], and thus that communities would be first and foremost physical besides virtual.

The results of the futures clinique point to new inequalities in the peer-to-peer model of work. Those who do not share the "unique ethos" might find it hard to be occupied, as social and cultural capital become crucial for success in a world of material abundance. Moreover, the requirement for uniqueness demands that workers self-define their jobs. Thus, even new inequalities and conflicts would be related to meanings, as they would become the "currency" on which people would compete. Without high cultural and social capital and self-knowledge workers are not able to define and create their own jobs.

Let us assume that in the future much of the reward in work comes from intrinsic motivation and bottom-up driven modes of organisation. What would it require for individuals and communities to become the units of production and exchange? What kind of policy requirements would this development impose? Firstly, it would require the like-minded to find each other. In the futures clinique an artificial intelligence application and different algorithms were suggested to bring people with the same interests and tastes together. Benkler [3] suggests that ubiquitous communication promotes likeminded to come together and allocate projects to the most suitable persons. Secondly, a universal basic income would not only redistribute wealth but help in liberating human potential for projects deemed important. If tested in different countries in the coming years, these solutions might emerge in time for the increasingly networking economy. Thirdly, while novel technologies, and their convergence, will set the context of operation, the way they are taken into use will require an ethical approach. The service economy debate has been driven by the technology-unemployment juxtaposition, but politics and policies may have to address these social and human-centred aspects more deeply.

Therefore, we expect it to be important to avoid politics, and policies, from falling behind to ensure the legitimacy of the state. The positive, business-as-usual, and negative aspects of the self-actualisation economy are discussed in the Millennium Project's Future of Work/Technology 2050 scenarios [19]. Our futures clinique results seem to emphasise the positive opportunities found in the MP's If Humans Were Free - the Self Actualization Economy scenario. However, to even realise the pursuit of self-actualisation, through the inner qualities of meaningful work, supportive political actions are needed. For understanding the emerging impacts of the changing nature of work, key institutions, including labour unions and workers' movements, will have to revise their agenda, and organisations re-evaluate their managerial practices. A particular benefit of long-term preparedness and anticipatory governance may lie in the potential mitigation of emerging inequalities. As emphasised in our futures clinique, this may allow hindering tensions between those better and worse prepared for the demands of self-actualising peer-to-peer work in a digital meaning society.

Acknowledgments The authors gratefully acknowledge the public financing of Tekes - the Finnish Funding Agency for Innovation, for the 'Neo-Carbon Energy' project under the number 40101/14. 
Open Access This article is distributed under the terms of the Creative Commons Attribution 4.0 International License (http:// creativecommons.org/licenses/by/4.0/), which permits unrestricted use, distribution, and reproduction in any medium, provided you give appropriate credit to the original author(s) and the source, provide a link to the Creative Commons license, and indicate if changes were made.

\section{References}

1. Amara R (1981) The futures field: searching for definitions and boundaries. Futurist 15:25-29

2. Baumeister RF, Vohs KD, Aaker JL, Garbinsky EN (2013) Some key differences between a happy life and a meaningful life. J Posit Psychol 8(6):505-516

3. Benkler Y (2006) The wealth of networks how social production transforms markets and freedom. Yale University Press, London

4. Benkler Y (2002) Coase's penguin, or linux and the nature of the firm. Yale Law J 112(3):429. http://www.yale.edu/yalelj/112/BenklerWEB. pdf

5. Breyer C, Heinonen S, Ruotsalainen J (2016) New consciousness: a societal and energetic vision for rebalancing humankind within the limits of planet Earth. Presentation at the 17th International Futures Conference Futures Studies Tackling Wicked Problems. Turku 1112 June 2015

6. Breyer C, Heinonen S, Ruotsalainen J (2016) New consciousness: a societal and energetic vision for rebalancing humankind within the limits of planet Earth. Technological Forecasting \& Social Change, forthcoming

7. Brynjolfsson E, McAfee A (2014) The second machine age. Work, progress, and prosperity in a time of brilliant technologies. W.W Norton \& Company, New York

8. Budhathoki NR, Haythornthwaite C (2012) Motivation for open collaboration: crowd and community models and the case of OpenStreetMap. Am Behav Sci 57(5):548-575

9. Castells M (1997) The power of identity. The information age: economy, society and culture vol. II. Blackwell, Oxford

10. Castells M (1996) The rise of the network society. The information age: economy, society and culture vol. I. Blackwell, Oxford

11. Drexler EK (2013) Radical abundance. How a revolution in nanotechnology will change civilization. Public Affairs, New York

12. Ferguson, CJ (2016) Social media, societal changes, and mental health: you can live online wholesale. In: SH Friedman (ed.) Encyclopedia of Mental Health (Second Edition). Academic Press, Oxford, pp. 179183. doi:10.1016/B978-0-12-397045-9.00068-9

13. Ford M (2016) Rise of the robots: technology and the threat of a jobless future. Basic Books, New York

14. Forte A, Lampe C (2013) Defining, understanding, and supporting open collaboration: lessons from the literature. Am Behav Sci 57(5):535-547

15. Fricker A (2001) The hunger for meaning. Futures 33:171-180

16. Gallouj FK, Weber M, Stare M, Rubalcaba L (2015) The futures of the service economy in Europe: a foresight analysis. Technol Forecast Soc Chang 94:80-96

17. Glenn, JC (2009) The futures wheel. In: JC Glenn, TJ Gordon, Theodore (eds.) Futures Research Methodology 3.0. CD-ROM, ACUNU: The Millennium Project, Washington, D.C

18. Glenn JC, Florescu E, the Millennium Project Team (2015) 201516 State of the Future. The Millennium Project, Washington

19. Glenn JC, the Millennium Project Team, Real-Time Delphi Participants (2016) 2050 Global Work/Technology Scenarios. Draft. Millennium Project

20. Goertzel B, Goertzel T, Goertzel Z (2016) The global brain and the emerging economy of abundance: mutualism, open collaboration, exchange networks and the automated commons. Technological Forecasting \& Social Change. Article in press

21. Heinonen S, Karjalainen J, Ruotsalainen J (2016) Neo-carbon energy scenarios 2050. Neo-Carbon Energy Working Paper 1/2016. University of Turku. Forthcoming

22. Heinonen S, Karjalainen J, Ruotsalainen J (2015) Towards the third industrial revolution. Neo-Carbon Energy Futures Clinique I. Finland Futures Research Centre e-Book 6/2015. Finland Futures Research Centre, Turku. www.utu.fi/fi/yksikot/ffrc/julkaisut/etutu/Documents/FFRC-eBook-6-2015.pdf

23. Heinonen S, Ruotsalainen J (2013) Futures Clinique - method for promoting futures learning and provoking radical futures. Eur $\mathrm{J}$ Futur Res 1:1-11. doi:10.1007/s40309-013-0007-4

24. Hinterseer T (2013) Part-time work: atypical? precarious? normal? Eur J Futur Res 1:1-8. doi:10.1007/s40309-013-0018-1

25. ILO (2016) World Employment Social Outlook 2016: Transforming Jobs to End Poverty, International Labour Organisation, Geneva. http://www.ilo.org/wcmsp5/groups/public/—dgreports/—dcomm/— publ/documents/publication/wcms 480911.pdf

26. Kostakis V, Niaros V, Giotitsas C (2015) Production and governance in hackerspaces: a manifestation of Commons-based peer production in the physical realm? Int J Cult Stud 18(5):555-573. doi:10.1177/1367877913519310

27. Lacity M, Willcocks L (2016) Service automation: robots and the future of work. Steve Brookes Publishing

28. Langlois G (2014) Meaning in the age of social media. Palgrave MacMillan, New York

29. Li FGN, Trutnevyte E, Strachan N (2015) A review of sociotechnical energy transition (STET) models. Technol Forecast Soc Chang 100:290-305

30. Mason P (2015) Postcapitalism. A guide to our future. Farrar, Straus and Giroux, New York

31. Nussbaum MC (2011) Creating capabilities: the human development approach. Harvard University Press, Cambridge

32. Orsi C (2009) Knowledge-based society, peer production and the common good. Cap Class 33:31-51

33. Pew Research Center (2014). AI, robotics, and the future of jobs. http:/www.pewinternet.org/2014/08/06/future-of-jobs/

34. Pew Research Center (2010) Millennials: confident. Connected. Open to change, pew research centre, February 2010. www. pewsocialtrends.org/2010/02/24/millennials-confident-connectedopen-to-change/

35. Rifkin J (2014) The zero marginal cost society. The internet of things, the collaborative commons, and the eclipse of capitalism. Palgrave MacMillan, New York

36. Rifkin J (2011) The third industrial revolution: how lateral power is transforming energy, the economy, and the world. Palgrave MacMillan, New York

37. Rifkin J (2009) The empathic civilization: the race to global consciousness in a world in crisis. TarcherPerigee

38. Ritzer G (2014) Prosumption: evolution, revolution, or eternal return of the same? J Consum Cult 14(1):3-24. doi:10.1177/1469540513509641

39. Sen A (1999) Development as freedom. Oxford University Press, Oxford

40. Singleton A, Abeles P, Smith IC (2016) Online social networking and psychological experiences: the perceptions of young people with mental health difficulties. Comput Hum Behav 61:394 403. doi:10.1016/j.chb.2016.03.011

41. Susskind R, Susskind D (2015) The future of the professions: how technology will transform the work of human experts. Oxford University Press, Oxford

42. UN (2016) Sustainable development goals, goal 7: ensure access to affordable, reliable, sustainable and modern energy for all. www.un. org/sustainabledevelopment/sustainable-development-goals/ 